\title{
Review of Macadamia Production in Malawi: Focusing on What, Where, How Much Is Produced and Major Constraints
}

\author{
Emmanuel Junior Zuza ${ }^{1, *} \mathbb{1}$, Kadmiel Maseyk ${ }^{1}$, Shonil Bhagwat ${ }^{2}$, Andrew Emmott ${ }^{3}$, Will Rawes ${ }^{3}$ \\ and Yoseph Negusse Araya ${ }^{1}$ \\ 1 School of Environment, Earth and Ecosystem Sciences, Faculty of Science, Technology, Engineering \& \\ Mathematics, The Open University, Gass Building, Walton Hall, Milton Keynes MK7 6AA, UK; \\ Kadmiel.Maseyk@open.ac.uk (K.M.); Yoseph.Araya@open.ac.uk (Y.N.A.) \\ 2 School Social Sciences and Global Studies, Faculty of Arts \& Social Sciences, The Open University, \\ Gass Building, Walton Hall, Milton Keynes MK7 6AA, UK; Shonil.Bhagwat@open.ac.uk \\ 3 The Neno Macadamia Trust, 42 Harpur Street, Bedford MK40 2QT, UK; \\ chair@nenomacadamiatrust.co.uk (A.E.); will@nenomacadamiatrust.org (W.R.) \\ * Correspondence: Emmanuel.Zuza@open.ac.uk; Tel.: +44-792-640-0636
}

check for updates

Citation: Zuza, E.J.; Maseyk, K.; Bhagwat, S.; Emmott, A.; Rawes, W.; Araya, Y.N. Review of Macadamia Production in Malawi: Focusing on What, Where, How Much Is Produced and Major Constraints. Agriculture 2021, 11, 152. https://doi.org/ 10.3390/agriculture11020152

Academic Editor:

Bettina Eichler-Löbermann

Received: 19 January 2021

Accepted: 10 February 2021

Published: 12 February 2021

Publisher's Note: MDPI stays neutral with regard to jurisdictional claims in published maps and institutional affiliations.

Copyright: (c) 2021 by the authors. Licensee MDPI, Basel, Switzerland. This article is an open access article distributed under the terms and conditions of the Creative Commons Attribution (CC BY) license (https:// creativecommons.org/licenses/by/ $4.0 /)$.

\begin{abstract}
Macadamia is an essential commodity crop in Malawi. The nuts are a lucrative commodity and are used for household consumption, income generation among farming families and as a foreign exchange earning crop at country-level. Macadamia production in Malawi has increased significantly in recent years. Malawi is the seventh top producer of macadamia nuts valued at $£ 23.5$ million, with a global market share of $3 \%$. In 2018, the country was the fourth-largest exporter of macadamia nuts that were valued at $£ 18.2$ million. The majority (90\%) of this crop was grown by large commercial estates with smallholder's production only contributing about $10 \%$ of the total crop production. However, the smallholder sector is vital for the future growth of the macadamia sector in the country. Further, Malawian smallholders consider macadamia production as a low-input crop with large returns per unit area $\left(£ 10.7 \mathrm{~kg}^{-1} \mathrm{ha}^{-1}\right)$, and it thus a lucrative commodity with high potential for poverty reduction and wealth creation among these farming families. This paper, therefore, explores: (i) the historical and current trends in macadamia nut production in Malawi; (ii) analyses the country's macadamia value chain focusing on smallholder farmer contributions; and (iii) discusses the constraints of smallholder macadamia production in Malawi for informed policymaking. We conclude that the synthesis of the Malawian macadamia sub-sector provides an understanding of the vital contributions of macadamia to Malawi's economic growth and improvement of livelihoods.
\end{abstract}

Keywords: macadamia nuts; lucrative; consumption; income generation; smallholder farmers; low-input crop; poverty reduction; wealth creation

\section{Introduction}

Malawi is a landlocked nation in southern Africa and located between Mozambique in the south-east and south-west, Zambia in the north-west, and Tanzania in the north-east. According to the Population Pyramid, the country covers an area of $118,484 \mathrm{~km}^{2}$, with a rapidly growing population of over 18 million inhabitants. The economy and food security of Malawi is heavily agro-based [1]. The sector contributes $46 \%$ of the country's gross domestic product (GDP) and accounts for $82.5 \%$ of its foreign exchange earnings [1]. The Malawian agrarian sector comprises of two distinct sub-sectors, i.e., the commercial estates and smallholder sub-sectors [2].

About $11 \%$ of the rural labor force works on commercial estates to supplement farm income, and around $80 \%$ is engaged in the smallholder sub-sector in Malawi [2]. Smallholder production accounts for $90 \%$ of all the food produced in Malawi, contributes over $25 \%$ of the entire country's GDP and employs 95\% of the total labor force [1]. These smallholders have limited livelihood options other than subsistence farming, with maize as the staple 
crop (occupying $60 \%$ of cultivated land) and tobacco as the main cash crop [3]. However, smallholder farmers are food insecure on an annual basis [4]. This is due to the utilization of traditional crop production methods, declining soil fertility, over-dependence on maize, and undeveloped livestock sector, which results in increased weather vulnerability that causes reduced productivity [5]. Malawi's smallholder agricultural sector is increasingly vulnerable to natural shocks, and climate change worsens the situation [6]. Therefore, the sector must adapt to these challenges for continued food and nutrition security within the country.

The promotion of climate-smart agricultural technologies, especially crop diversification, is vital for addressing smallholder farmers' issues in crop production in Malawi. Crop diversification encompasses two perspectives (horizontal and vertical diversification). Horizontal crop diversification is the addition of crops to an existing cropping system for the purposes of food security, soil fertility improvement and diet diversification, and vertical crop diversification as the addition to an existing system of high-value crops that can be processed and exported for income generation [7]. Among Malawians, maize is the main staple and most important food crop and predominantly grown by smallholder farmers [8]. However, Reference [9] found that by 2055, maize yields will decline by $50 \%$ in Malawi due to precipitation changes. Until recently, the mainstay of the rural economy has been tobacco, and currently, 95\% of the production output is by smallholders [4]. However, with the negative market trend of tobacco and the changed strategy by tobacco buying companies, smallholders require alternative cash crops for their survival.

The government of Malawi is keen on reducing its dependence on maize and tobacco, as demonstrated by its explicit focus on diversification and sustainable agricultural transformation in Malawi's key policy frameworks, including the National Resilience Strategy (2018-2030) [4] and the National Export Strategy (2013-2018) [10]. In practice, the government supports the promotion of other food crops for consumption such as cassava, rice, sorghum, and sweet potatoes and traditional high-value cash crops such as common beans, groundnuts, coffee, macadamia, and tea [11]. However, the government of Malawi and various Non-Government Organizations have been putting more effort into macadamia production. This is because the crop is considered a lucrative crop among smallholder producers who utilize it to supplement their maize-based diets and sell it to export markets for income generation. As such, macadamia could be an alternative to both maize and tobacco in the future.

Macadamia (Macadamia integrifolia Maiden and Betche) is a species of evergreen trees indigenous to Australia's coastal rain forest areas but was first commercially cultivated in Hawaii [12]. Global macadamia nut production has continuously increased in recent years (Figure 1) and is expected to continue in the coming decade [13]. However, macadamia nuts production only accounts for less than $2 \%$ of the worldwide tree nut production [13]. The crop is predominantly grown in Australia, Brazil, China, Colombia, Costa Rica, Guatemala, Hawaii, Kenya, Malawi, and South Africa [13]. Smaller-scale cultivation has been reported in Argentina, Fiji, Jamaica, Mexico, Mozambique, New Zealand, Swaziland, Tanzania, Venezuela, Vietnam, and Zimbabwe. Under good management, macadamia trees can start bearing fruits two years after transplanting. However, the yield of macadamia trees tends to increase with tree age. Thus, trees ranging from 1-5 years can yield around $5 \mathrm{~kg}$ of nuts per tree per year, and older trees over 5 years have been reported to yield over $20 \mathrm{~kg}$ of nuts per year depending on the growing region [14].

Macadamia is an important lucrative crop in Malawi, especially among smallholder producers. The country is the seventh top producer of macadamia nuts globally (accounting for $3 \%$ of the world production on a five-year average) with the potential to become one of the top three leading producers in the next decade [15]. Malawi has a suitable climate and altitude conditions for macadamia production, and the vast tracts of land available in the country, especially in the central and northern regions, provide an area for expansion [15]. Despite this potential, macadamia nuts' contribution to Malawi's economic growth is not well documented [16]. At present, Malawi does not produce any macadamia finished 
products [17]. Almost all the macadamia nuts produced in Malawi are exported in their raw form to South Africa. According to the Neno Macadamia Trust (NMT), macadamia nuts contribute to Malawi's food security and foreign exchange earnings.

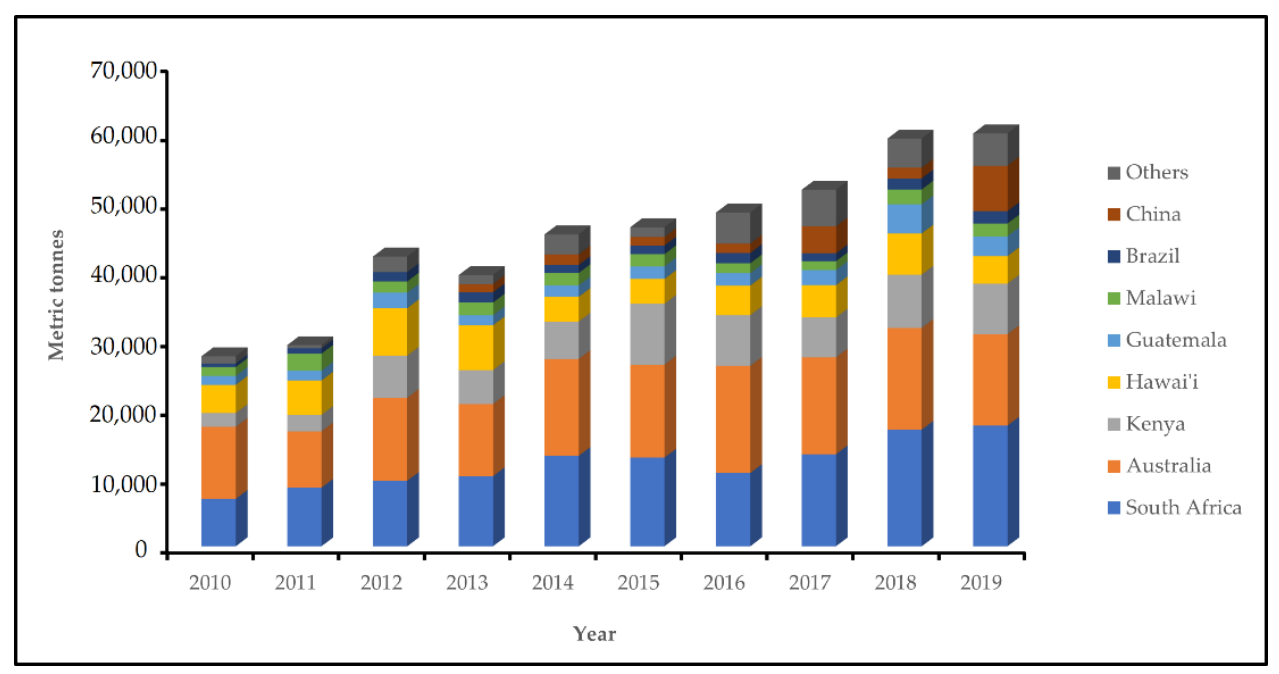

Figure 1. Macadamia kernel production depicting principal world producers.

For this reason, the Malawi government and the private sector can potentially take advantage of the growing world demand to promote the production of macadamia finished products for both local and export markets. There have not been any studies in the literature that provide a comprehensive review of the historical and current status of the macadamia sub-sector in Malawi and its contributions to food security and the country's economy. This is because most studies have mainly focused on important staple and cash crops [18]. This paper, therefore, provides a review of the macadamia sub-sector in Malawi, especially on (i) the historical and current production trends of macadamia nuts; (ii) the macadamia value chain structure, and (iii) the constraints facing smallholder macadamia production.

\section{Macadamia Production in Malawi: A Historical Background}

The first planting of macadamia trees in Malawi is not well documented. However, old trees (currently $\geq 80$ years old) believed to have been the first introductions and still surviving are found in Thyolo (Bvumbwe Agricultural Research Station), Ntchisi (Kalira Extension Planning Area), and Rumphi (Lunyangwa Agricultural Research Station) districts [19]. According to [20], these trees were introduced from Hawai'i for research trial purposes in Malawi in the early 1940s. The macadamia research was commissioned in response to the government of Malawi and commercial estates industry demands. The main research questions included:

- The evaluation of macadamia clones/cultivars from Hawaii for growth, yield, and adaptation under Malawi field conditions.

- Development of the macadamia value chain for the estate's sector as a substitution of tung plantations.

During the research phase, the macadamia nut sub-sector in Malawi was only based on commercial estates at the Naming'omba Tea Estate Limited, Eastern Produce, and Kawaladzi Estate and consisted of extensive land holdings, most of which existed before independence (1964) which were controlled by United Kingdom-based multi-national companies. The first commercial macadamia planting in Malawi was in the late 1960s, on Kumadzi estate in Thyolo district [20]. During this period (the 1960s-1980s), the commercial estates predominantly focused on coffee and tea production, while tung (Vernicia fordii) oil was a declining industry. While macadamia's hectarage was often large among the commercial estates, the crop was still considered to be of small importance in the overall 
estate production systems [19]. Macadamia was usually planted on poor land unsuitable for coffee and tea or as a replacement for tung oil trees [19]. Smallholder macadamia production started at about the same time as commercial estates production [20]. Commercial estates provided smallholders with macadamia seedlings for use as boundary crops. This was targeted to smallholders located close to Bvumbwe, Kalira, and Lunyangwa experimental sites. Smallholder production at the time was small and insignificant in terms of total production.

By the early 1980s, 17 estates had gone into operation, producing more than 311 metric tones of saleable macadamia kernel. Approximately $95 \%$ of all of this produce was processed respectively at Naming'omba Tea Estate Limited and Kawaladzi Estate factories [19]. According to a report published by the Malawi Tree Nut Authority, the 1989 production of saleable kernel amounted to 150 metric tonnes and returned $£ 750,004$. The yield's decline is attributed to the drought in the region during that year [21].

Smallholder macadamia production between the 1980s and 1990s was still in its infancy phase, with farmers abandoning the crop annually due to low pay-outs from the commercial estates and lack of organized market from the government [22]. In 1991, David Emmott, with his ex-foreman Timothy Kanthiti, who helped run the family farm in Neno district in the 1950s, started promoting smallholder planting of macadamia trees in Neno district. As a result of Emmott's activities, smallholder macadamia production started to spread to Mwanza, a district west of Neno. Realizing the potential of smallholder macadamia production to Malawi's economy, Malawi's government conducted a feasibility study on the suitability of smallholder macadamia production within the country (19901994). Coincidentally, the feasibility study on macadamia was coupled with significant reforms in the agricultural sector, including the deregulation of particular crops (coffee, tea, macadamia, and tobacco) and liberation of prices in 1995. As a result of macadamia nuts market potential and food value, in 1998, the Malawi government received funding from the African Development Bank to implement the Macadamia Smallholder Development Project (MSDP).

The geographical focus of the MSDP project included five districts in Malawi (Dowa, Mzimba, Ntchisi, Nkhatabay, and Rumphi). The project aimed to improve smallholder farmers' welfare by providing income-generating activities and increasing foreign exchange earnings for Malawi's agricultural sector through crop diversification [23]. Despite the potential and the keen interest from smallholder farmers, the MSDP project was regarded as unsuccessful and resulted in many farmers neglecting their macadamia trees after the project phased out (2007), opting for more profitable crops with established markets and support from the government. However, at the same time, the Neno Macadamia Trust was created with the aim of promoting smallholder macadamia production in Malawi. The Neno Macadamia Trust led to the creation of seven smallholder-owned cooperatives that currently fall under the Highlands Macadamia Cooperative Union Limited (HIMACUL) and are still vibrant.

\section{Macadamia Production in Malawi Today}

Macadamia is now a fully established crop and competes with other crops for land in Malawi [24]. Having been set up by the commercial estate sector, the macadamia industry is currently well established with strong growth potential [15,24]. The total hectarage has been increasing from 5280 hectares (ha) in 1996 to 9660 ha in 2019, an increase of $83 \%$. Further, approximately 1500 ha of the macadamia land is under smallholder management. Disaggregated, this represents a 35\% increase in the mature crop, a 4 -fold increase in immature trees [25]. Disaggregation between mature and immature trees is vital because it shows which trees are currently responsible for the macadamia nuts and the potential of the macadamia industry in the future. Figure 2 shows that annual plantings have been increasing, and 2019 recorded the highest annual plantings (1202 ha) in 20 years and an average of 980 ha per year since 2016. Furthermore, there has been an acceleration of new establishments: 1975 ha in the northern and central regions of 
Malawi, which accounts for almost half of the expansion during the period [25]. Currently, Malawi has 7 major producers who also facilitate in the processing and marketing of the nuts (Confodzi Estate, Naming'omba Tea Estate Limited, Eastern Produce and Plantation General International in Thyolo and Mulanje districts, Kawalazi Estates in Nkhatabay district, Sable Farming in Chiradzulu districts, and Tropha Estates in Mzimba district) alongside some 3850 smallholder farmers spread throughout the country $(90 \%$ of which are HIMACUL members).

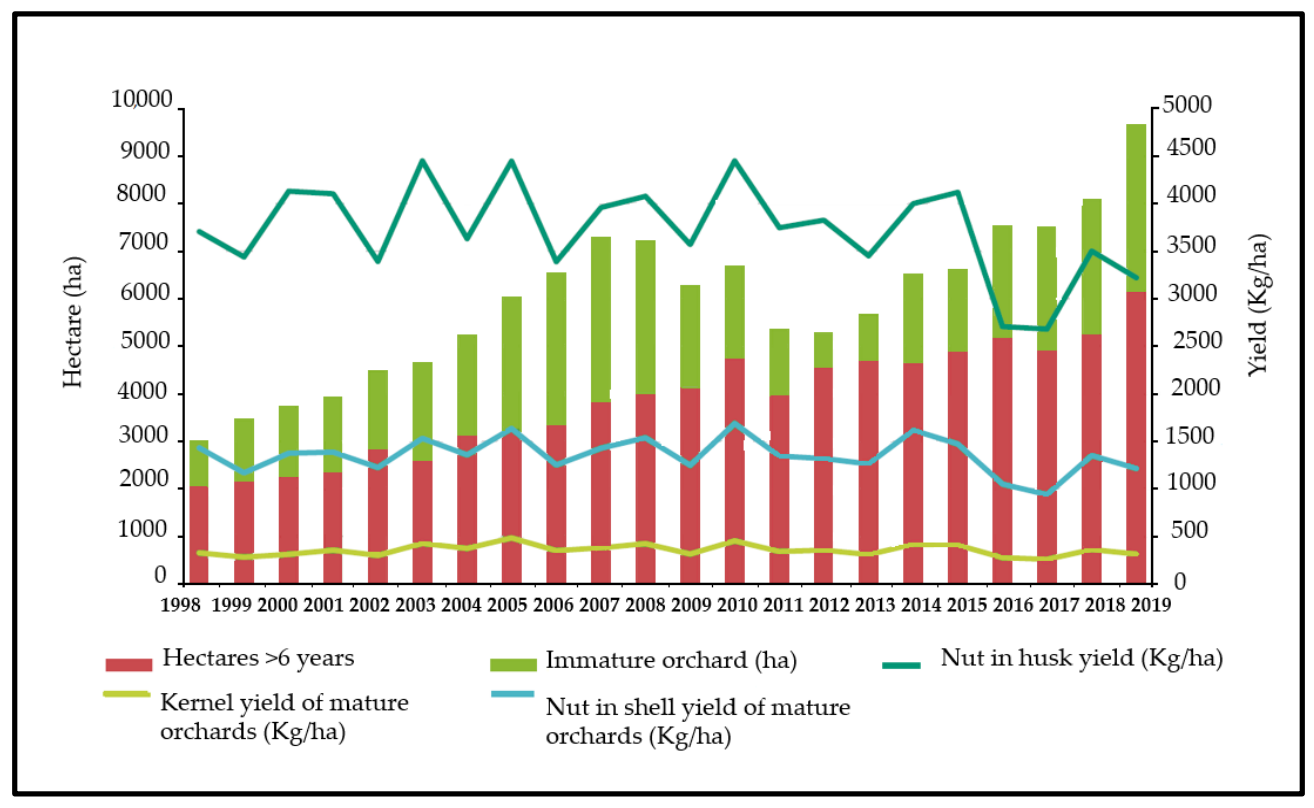

Figure 2. Area allocated to macadamia production and yields in Malawi based on orchard age.

Smallholder macadamia trees total over 300,000 compared to over one million under the commercial estate sub-sector. These numbers are expected to increase in the next decade due to government and private sector involvement in the value chain [25]. This is, in addition, to increase in popularity of the crop among smallholders in Chitipa, Dowa, Mwanza, Mzimba, Neno, Ntchisi, and Rumphi districts. Recently some smallholder activity has also been observed in Kasungu, Lilongwe, and Mchinji districts as well. Figure 3 shows the macadamia growing districts in Malawi. Light green shaded districts are those in which HIMACUL is actively operating, representing smallholder growers. The dark green districts are commercial macadamia plantations and processing locations. Pink shaded districts are those where activities are at an early stage of development or have a high potential for the establishment to be extended with HIMACUL targeted Extension Planning Areas.

Malawi currently has seven commercial macadamia processors and marketers [25]. Macadamia processing and marketing include firms that are either exclusively involved in the processing or marketing of macadamia nuts or in the combined activities of growing, processing, and marketing macadamia nuts. Like the South African and Kenyan macadamia industry, the Malawian macadamia industry is built around processors and marketers because they perform the leading share of the industry's value chain activities. These firms provide research and extension services to growers and develop new macadamia products and markets for existing and new products. Three predominant processors and marketers in Malawi (Naming'omba Tea Estate Limited, Sable Farming, and Tropha Estates) are involved in both production and processing of the crop from their farms and that of smallholder farmers, while Confodzi Estates, Eastern Produce, Kawalazi Estates, and Plantation General International focus on their production and processing [16]. Overall, processors and marketers are the leading parties determining the macadamia 
value chain's overall characteristics in Malawi [15,25]. Their responsibilities also include upgrading possibilities, knowledge transfer, and integration and coordination within the value chain.

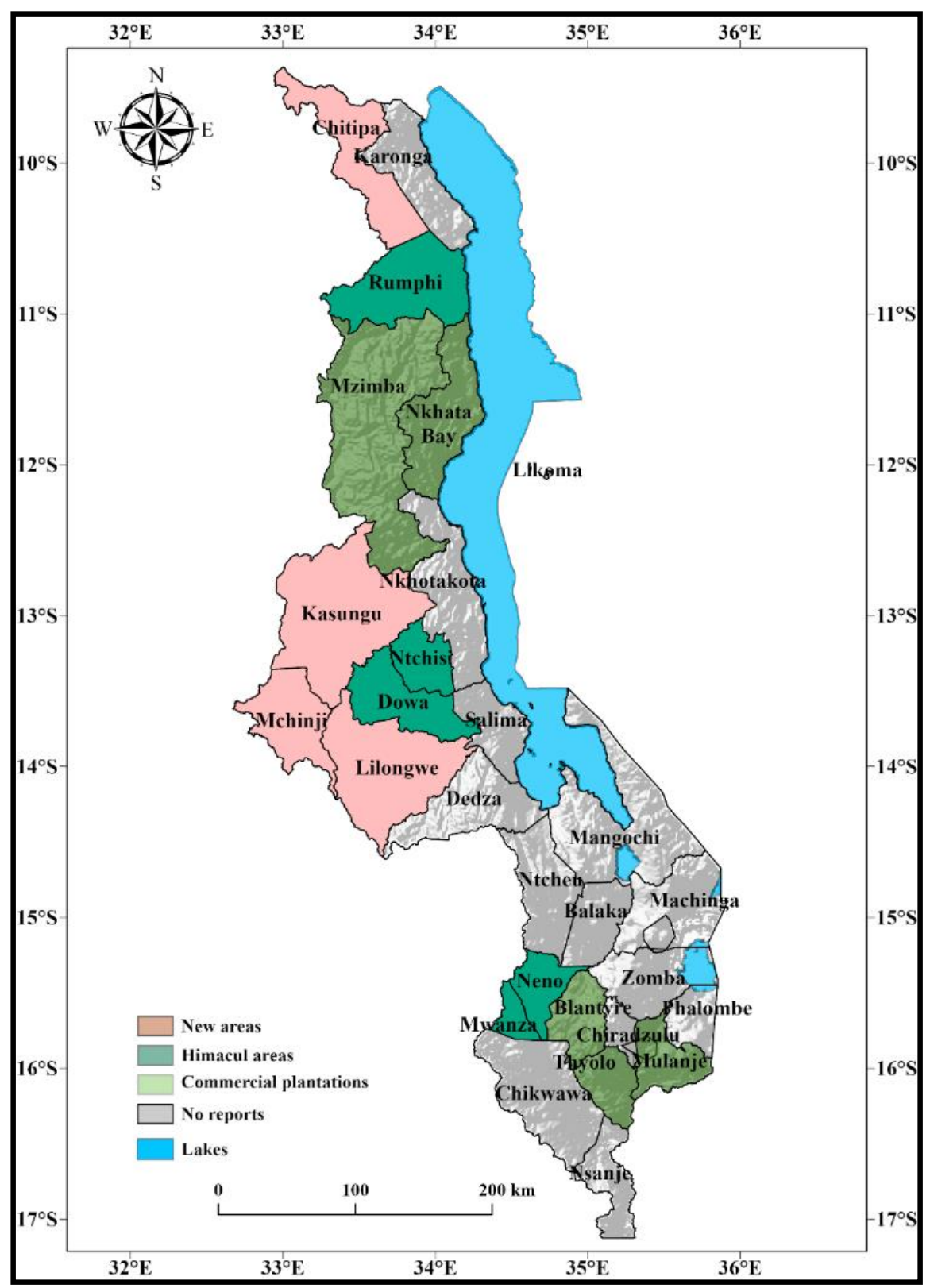

Figure 3. Macadamia growing areas in Malawi.

Historically Malawi was the third-largest macadamia producer globally (the mid1980s), but this declined over the years due to changes in ownership of the commercial estate plantation leaderships [19]. However, Malawi still has a strong competitive edge in growing its production base and can obtain its past rankings if managed properly. Moreover, demand for seedlings, particularly from smallholder farmers, has been increasing over the past decade, implying that the crop's hectarage is increasing [15]. Macadamia nut production in Malawi is almost entirely for exports, with a small (5\%) but growing volume of the nuts consumed locally [25].

Production of macadamia in Malawi has increased by 53.5\% over the last decade [13]. Production growth is attributed to an increase in smallholder tonnage of the nuts (HIMACUL), access of smallholders to processing facilities, and the modernization of the 
Naming'omba Tea Estates Limited processing plant in 2015 (Figure 4). Additionally, with the bulk of smallholder young orchards only starting to produce, or not yet producing, it is expected that the Malawian crop will double in volume in the next two to five years [26]. In some years, significant decreases in yields were incurred $(2006,2009,2010,2016,2017$, and 2019) owing to erratic weather events, especially droughts and flooding. Another factor affecting macadamia yields are pests and diseases. Specifically, macadamia stink bugs and fruit borers can cause up to $100 \%$ yield losses depending on the location of the orchard.

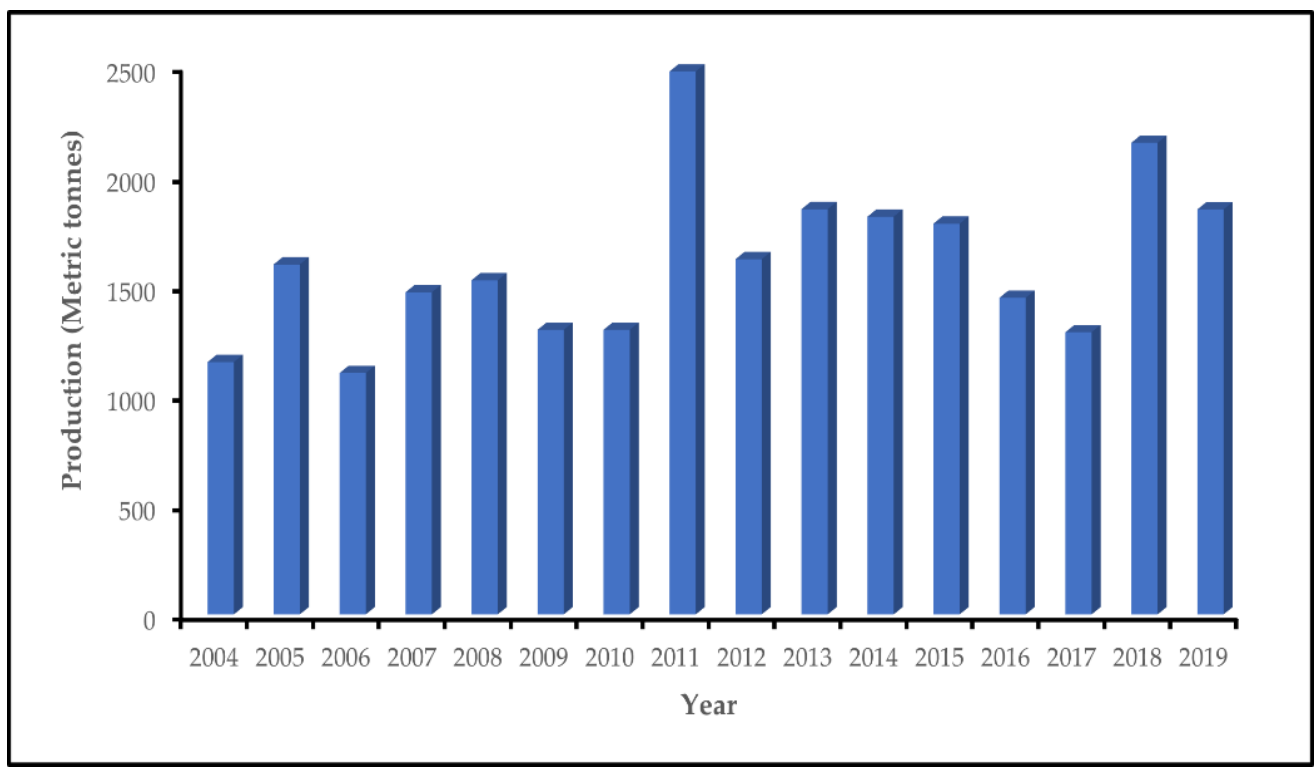

Figure 4. Macadamia kernel production trends in Malawi (2004-2019).

\section{Macadamia Exports from Malawi}

Malawi is currently the fourth largest exporter of macadamia nuts worldwide (Figure 5), accounting for about $5 \%$ of the global trade on average [13]. Observations on the average prices for macadamia kernel imports shows an upward trend in the last five years: the average price across all imports increased from $£ 9589$ (2013) to $£ 13,130$ (2018) per metric tone [24].

In terms of exports, between $90 \%$ and $95 \%$ of Malawi's macadamia are produced for export. The key export destination for Malawian macadamia is South Africa, primarily for the snacking market. Malawi is expected to have new export markets in China and Vietnam due to the increasing demand for the nuts and its products, as shown in Figure 6. In addition, between 2014 and 2019, Kyrgyzstan and Malaysia, who had been traditionally been kernel importers, started to import NIS macadamia from Malawi. Thus, expanding the NIS market for the produce for Malawian farmers. The majority of the macadamia export volumes from Malawi are sourced from commercial estates rather than smallholder farmers. This is due to the lack of upstream traceability by the smallholders and independent buying by middlemen. Adopting traceability systems and the creation of a registry of smallholder farmers could assist in addressing this problem. 


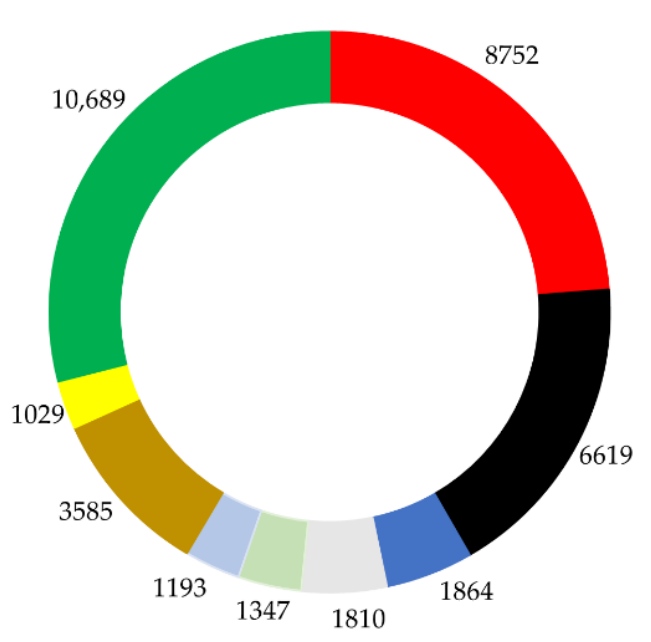

- South Africa, $29 \%$

- Australia, $24 \%$

Kenya, $18 \%$

China*, $4 \%$

Netherlands**, $5 \%$

플 USA, $3 \%$

Guatemala, $3 \%$

Malawi, $5 \%$

Others, $9 \%$

* Processing country

** Transit country

Figure 5. Macadamia kernel exports depicting principal exporters globally.

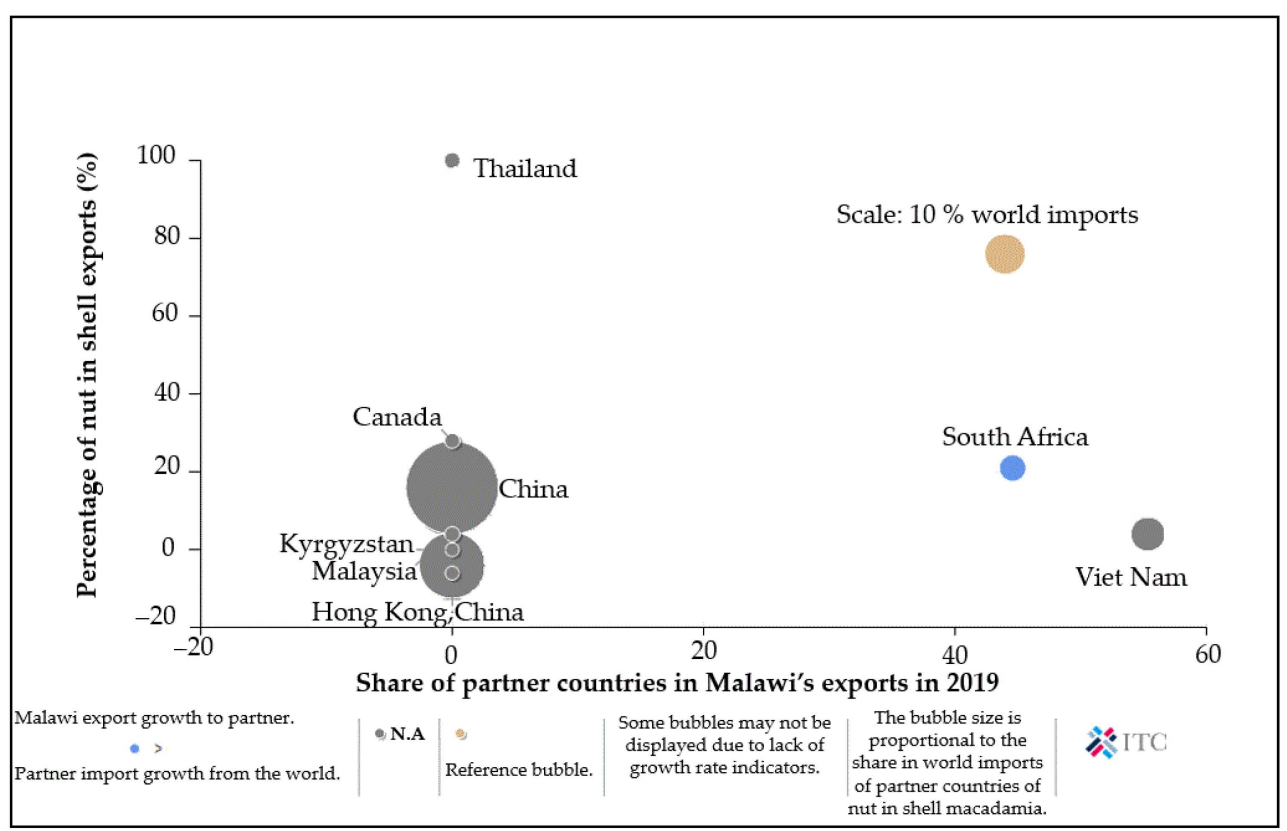

Figure 6. Growth of Malawi's macadamia nut is shell exports to the partner countries between 2014 and 2019.

\section{The Macadamia Supply Chain in Malawi}

The Malawian macadamia value chain comprises of producers (commercial estates and smallholders), aggregators (traders and associations), processors, and influencer organizations. Leading influencers in Malawi's macadamia value chain includes the Ministry of Agriculture, Irrigation and Water Development, Malawi Bureau of Standards, Ministry of Industry, Trade and Tourism, the Tree Nut Growers Association of Malawi, and HIMACUL. Other stakeholders supporting the macadamia value chain are AgDevCo and Deutsche Gesellschaft für Internationale Zusammenarbeit (GIZ). The visual mapping of Malawi's macadamia value chain is shown in Figure 7. 


\subsection{Producers (Commercial Estates and Smallholder Farmers)}

Commercial estates dominate macadamia production in Malawi and account for over $90 \%$ of the total production, with some 3850 smallholders spread out over the southern (Mulanje, Mwanza, Neno, and Thyolo districts) and central (Dowa and Ntchisi districts) regions in the country, representing about $10 \%$ of the production. Until recently, smallholder production was concentrated in these two regions in Malawi. In 2013, Tropha Estates established a macadamia processing plant in the northern region of Malawi, which has led to an increase in smallholder macadamia planting in the region, especially in Chitipa, Mzimba, Nkhatabay, and Rumphi districts [16]. Additionally, smallholder macadamia production has also started to take shape in Mchinji, Lilongwe, and Kasungu districts, located in the country's central region. The bulk of the macadamia expansion in terms of area and volumes predominantly emanates from existing farmers expanding primary operations, while new entrants contribute very little growth into primary production [27].

Farming units for macadamia production among smallholder farmers vary in size and range from tiny $(\leq 0.1 \mathrm{ha}$ ) to larger profitable farms ( $\geq 4 \mathrm{ha})$. However, most smallholder macadamia producers individually do not produce sufficient volumes $\left(\leq 100 \mathrm{~kg} \mathrm{ha}^{-1}\right)$ to justify the time and capital investment involved in processing and market development. These key-value chain activities of processing and marketing have been taken on by a few large-enough horizontally integrated individual commercial estates such as Naming'omba Tea Estates Limited and Kawalazi Estates [16,27]. Due to this, the buying and selling power in a small market like macadamia, is concentrated in the hands of a few large commercial estates that ultimately control the industry value chain. While the control of the industry value chain by these commercial estates is not ideal, in terms of extending smallholder macadamia production, without them, it would fail [27].

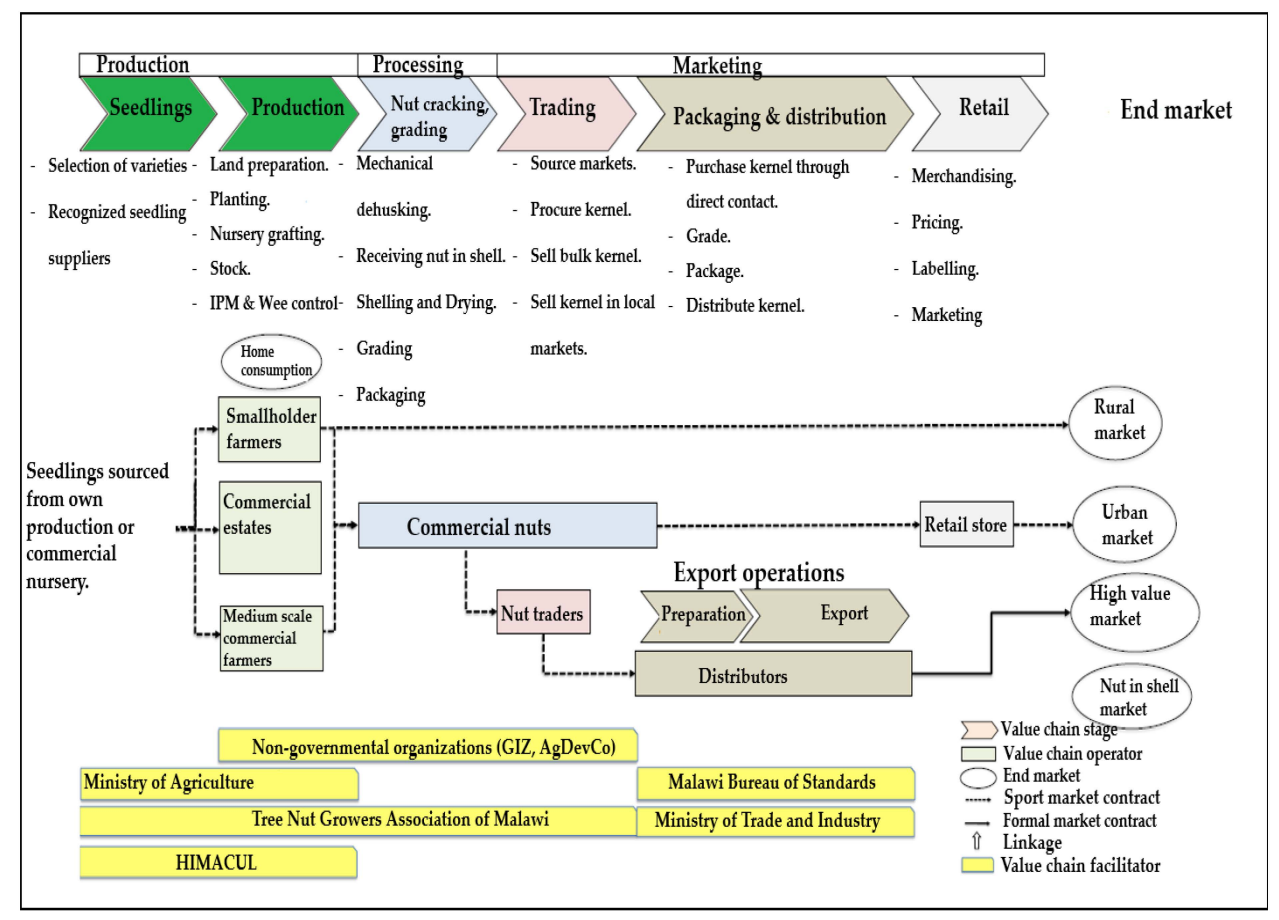

Figure 7. Macadamia value chain actors in Malawi.

Individual growers have a choice of delivering nuts to any of the seven commercial estates for processing. These individual farmers often tend to sell some of their nuts to intermediaries, who later deliver them to the processors. This is attributed to long distances between the smallholder producing areas and the processing facilities. In contrast, HIMACUL members aggregate their nuts in their respective cooperative business centres, which are further dried to a moisture content of less than $5 \%$ and are later delivered 
to HIMACUL central warehouses in Ntchisi or Neno. HIMACUL takes responsibility for further drying and grading of the nuts before delivering them to the commercial estates (processors).

With high pest and disease incidences, the relevance of agricultural input supply shops cannot be overemphasized. To facilitate access to farm inputs, HIMACUL provides input loans (such as; seedlings and fertilizer) to their member cooperatives and individual clubs, which is repaid at the end of each harvest season. The same has been reported to the in-grower smallholders associated with the PMs. Macadamia seedlings are mainly sourced from HIMACUL and estate nurseries. Some farmers, especially members of HIMACUL, produce their seedlings through grafting techniques for their use and sell the excess to other farmers.

\subsection{Nut Vendors or Middlemen}

Macadamia nut vendors or go-betweens are unregistered buyers of macadamia nuts. The vendors buy macadamia nuts from farmers at farm gate prices and sell them again to registered traders or processors. Therefore, the central role of vendors is buying and assembling the nuts. Vendors do this through door to door buying and involve the use of pails and tins as standard measures at pre-established non-negotiable prices. They're predominantly men as the activity of buying requires much heavy lifting of produce, walking long distances, and spending long periods away from home. Often vendors are perceived as dishonest because they buy macadamia nuts cheaper from farmers than cooperatives and commercial estates and usually buy the crop without any quality specification. For example, farmers had reported instances when vendors bought the crop while it was still not adequately dried during times of financial hardship, such as when school fees and other household necessities are due, especially in January.

\subsection{The Highlands Macadamia Cooperative Union Limited (HIMACUL)}

The Highlands Macadamia Cooperative Union Limited conducts and coordinates various activities of seven primary cooperatives in Malawi. HIMACUL is involved in macadamia nut aggregation activities, including bulking of macadamia nuts from its member farmers, further drying and grading of the crop, and further facilitation in the transportation of the nuts to processors and trading. Furthermore, HIMACUL works with its membership to establish nurseries, tree planting, tree surveys, natural resource conservation (soil and water management), crop diversification (inter-planting groundnuts and maize in macadamia orchards), infrastructure development, and market linkages to interested macadamia buyers. In 2015, HIMACUL developed a five-year plan (20162021), intending to intensify macadamia activities, and created a Plan Vivo payment for its farmers' ecosystem services.

The Plan Vivo is a framework for supporting rural smallholder farmers and communities to manage their natural resources more sustainably for their livelihoods and wellbeing, to generate climate, livelihood, and ecosystem benefits. Participants undertake decision-making on the land uses to be implemented, for example, woodlots, orchards, agroforestry, and forest conservation [28].

\subsection{Macadamia Processors}

The Malawian macadamia industry receives very little assistance in infrastructure development from the Malawi government [16]. Therefore, it is consisted of privatelyowned processing plants that perform the complete and fundamental processing procedure, covering dehusking, nut in shell grading, curing, cracking, kernel grading, and packaging.

Marketing is the core responsibility of the processors who find buyers and negotiate a price for the product. Apart from adding value to macadamia by processing and packaging it, processors also act as traders, in that they aggregate small amounts of the crop through vendors. However, no governing authority for macadamia exists, and the processors themselves determine commission tariffs. 
Currently, there are seven processors of macadamia nuts in Malawi [17]. These processors are mainly involved in dehusking and packaging of the raw nuts for international markets. Presently the processors only produce roasted macadamia mainly for the domestic market (around $5 \%$ of the nuts). The remaining $95 \%$ of the raw nuts are exported to South Africa. However, processors would be interested in supplying retailers globally with macadamia snacks. One way to realize this could be to use the retailers' packaging to produce these nuts in Malawi. While this is feasible for the Malawian value chain, the potential of this is questionable for the international retailers and would require a scoping study on their interests. Another possible solution, especially among the smallholder producers, is through fair trade certification of their cooperatives. This would ensure that smallholders get premiums for their nuts.

\subsection{Tree Nut Growers Association of Malawi}

The Tree Nut Growers Association of Malawi (TNGAM) acts as the bridge between macadamia processors and producers. TNGAM is also responsible for representing Malawi nut growers globally [15]. However, according to our conversations with smallholder farmers, the organization has not been as vibrant as it could have been, and it is described as not fulfilling its duties.

\subsection{Non-Governmental Organizations (NGOs)}

Various non-governmental organizations play different roles in the macadamia value chain in Malawi. For example, GIZ has been working on improving the macadamia value chain by promoting more smallholder farmers in macadamia production as a way of diet and income diversification, training smallholders in farm business management, and facilitation of linkages between public and private actors within the value chain Another influential NGO in the Malawi's macadamia value chain is AgDevCo, a social impact investor and fund manager. The primary role of $\mathrm{AgDevCo}$ has been investments in improved technologies of production and processing facilities [16]. According to [27], AgDevCo invested $£ 1.6$ million in Tropha Estates in 2014 to develop a 518 ha irrigated macadamia hub farm and a 1000 metric tonnes processing facility.

\subsection{Wholesalers, Retailers, and Value-Adding Sector}

Macadamia nuts from Malawi are mostly sold as a nut in shell to South African traders who pack and distribute the nuts in the European snacking market [29]. Macadamia kernel finds its way to the European and USA market as ingredients in candy and confectionery. Recently, packers of snacking food also roast and flavor macadamia kernel, after which it is packed as part of a nut mix or pure macadamia snack pack destined for the snacking market both locally and internationally. Sound kernels are not suitable for the snacking, candy, or confectionery markets and are processed into oil or macadamia butter. Macadamia oil is used as a salad dressing or cooking oil or as a base for lotions and creams in the cosmetic industry. Macadamia butter is used as a spread or as a base for pesto and flavoring.

Macadamia shells have various applications that include being processed into charcoal briquettes, pressed board wood products, brake linings, sandblasting agents, and carbonated shells used to filter water. In unprocessed form, macadamia shells are used as mulch in gardens and fuel in the boilers of the macadamia processing plants and for cooking or warming water.

Despite considerable investments in processing facilities for macadamia nuts by the private sector in Malawi, presently, no finished products are produced within the country. Most of the nuts are sold in their raw form both in the local and international markets. This results in low market prices for the unprocessed product. However, to increase the profitability of macadamia nuts in Malawi, there is a need for value addition. In 2019, Nutcellars, a UK based startup company, started to process macadamia nuts sourced from HIMACUL smallholder farmers into various products such as butter and chocolate. This shows the potential of further processing the crop in Malawi. With increased popularity 
and demand for the nuts among local consumers in Malawi, it is important to venture in macadamia processing.

\section{Agricultural Policy Analysis in Malawi and Its Link to Smallholder Macadamia Production}

Food security is termed as a channel for economic growth and a means to reduce poverty in Malawi. As stated in the Malawi Growth and Development Strategy 2011-2016 II (MGDS II), the government has designed effective policies to initiate improvements in the agricultural sector. To achieve this objective, the National Export Strategy (NES) promotes agribusiness with enhanced competitiveness in the export market [30]. The main motivations behind the NES have been the slow rate of growth of exports as compared to imports that have resulted in a trade deficit. Consequently, the NES helps Malawi diversify its range of agricultural exports with improved production and economic benefits.

When it comes to agricultural exports in Malawi, it is essential to look at how relevant policies have evolved. According to the Agriculture Sector Wide Approach Programme (ASWAP), the three main focus areas include (1). ensuring food security and managing risk, (2). developing the commercial market and (3). providing sustainable land and water management. The bulk of the policies has aimed to revitalize the export sector, and the policies have therefore addressed oilseeds and sugar cane products and manufacturers.

After a thorough analysis of Malawi's agriculture sector, it has been determined that the groundnuts value chain is the most efficient for future investment opportunities [30]. To understand how the agriculture sector functions, it is vital to discuss the existing policies for cash crops. One of the prominent policies was introduced in Malawi in 2005-2006 under the name of Farm Input Subsidy Program (FISP) to facilitate smallholder farmers to overcome the high cost of inputs.

Moving on to the liberalization phase, Malawi has faced some severe restrictions in the agricultural market. Apart from this, the agriculture export commodities face trade flow obstacles. These include delays at trade clearance and challenges to acquire export licenses. [30], provide a comprehensive layout of the agricultural framework adopted in Malawi and the challenges to the export market. They outline the roadblocks of production to farmers and highlights the ways these can be addressed. However, more research is needed to judge the impact of FISP in Malawi and whether there are better investment opportunities available.

It is critical to assess the previous agricultural policies adopted by Malawi for agricultural support and the circumstances that led to FISP. Starting in 1998, the government introduced the starter pack supported by the UK Department for International Development [31]. Directed towards smallholder farmers, the starter pack was designed to hand out various seeds to help farmers double their outcomes. Due to financial constraints and poor logistical handling, the Targeted Inputs Program (TIP) replaced the starter pack. With a restricted beneficiary size, TIP failed to improve and headed for its decline amidst a food crisis.

FISP was introduced to tackle the food crisis in Malawi, with the following aims; to eliminate leakage of input exports across the country borders and it was to target $60 \%$ of the productive farmers. With an increased focus on productivity, FISP was designed to leave out $20 \%$ of the most impoverished farmers. This specific targeting was problematic, and therefore, the entire focus shifted away from productivity. To understand the main issue here, it is crucial to understand that the productive poor remain poor regardless of their output.

The current situation calls for a change. However, is the government ready to abandon FISP in the hopes of a better program? The answer is probably "No" as the process has become highly politicized, and farmers feel entitled to the FISP [31]. With policy inconsistency, Malawi finds it difficult to both retain food security and economic stability. The future path of action will include the government coming up with a better improved version of FISP taking into account the perils of poverty. 
Building upon the current agricultural policies, Malawi's government has developed strategies to deal with product-specific constraints. In 1993, the government noticed the low participation of smallholder farmers in the Macadamia industry. Upon exploration, the results revealed that the lack of technical knowledge, direct access to relevant markets, and a weak market structure caused a hindrance for smallholder farmers to take part in the value chain [23]. The interest in macadamia production is attributed to low maintenance and easy cultivation process compared to other cash crops. Moreover, macadamia can be paired along with other crops, thus increasing the gains per area.

Based on such characteristics, the Agriculture and Livestock Development Strategy Plan 1995 worked towards promoting the crop. As a result of government efforts to gain funds, Macadamia Smallholder Development Project (MSDP) was launched to help smallholder farmers to actively participate in the production and eventually reduce poverty. Aimed towards economic stability, the main goal of MSDP was to initiate the cultivation of 500 hectares of land in rural areas [23]. A detailed overview of MSDP outlined six critical components:

- Promoting nursery development.

- Promoting crop development.

- Improving research and extension programs.

- Helping capacity building.

- Managing infrastructure development.

- $\quad$ Supervising project management.

Assessing the socio-economic impact of MSDP, it was found out that the project increased women's participation in macadamia nut production. This is expected to improve nutrition value in the region as women use them for their children's meals. With minimum impact on the environment, the MSDP has successfully achieved its set targets with cultivating a total of 1320 hectares of land (African Development Bank, 2009), whereas areas like infrastructure development were less successful and under consideration for improvements.

The MSDP report shows that, if implemented correctly, macadamia production can eventually help alleviate the poverty constraints in Malawi's rural areas. With these objectives in focus, the government has laid out some policy interventions to tackle product constraints in agricultural production [11]. The primary constraint was identified as a low supply of nuts due to inadequate production capacity and productivity. Some of the proposed interventions included:

- The Ministry of Agriculture, Irrigation and Water development (MoAIWD) to generate funds for the research and development for climate adaption to lower the kernel recovery ratio of macadamia nuts.

- Support of commercial farmers for smallholder farmers to establish nurseries and arrange for necessary supplies.

- As a part of the integrated business program, smallholder farmers to be connected to reliable markets and partnered with the private sector.

- With the help of MoAIWD, smallholder farmers should be trained under the guidance of experts from the US.

- Other constraints identified include a lack of technical experts and working capital for macadamia production. Without addressing these obstacles, it is difficult for smallholder farmers to improve production as well as productivity. The government put forth the following agendas to assist: With the collaboration of HIMACUL and MoAWID to conduct a skills audit to gather experts and their expertise.

- MoAWID and HIMACUL to help farmers uncover the relevant skills for the sector and work on essential training programs to bridge the gap.

- Ministry of Finance to work towards developing reliable funds and a bank reserve.

- Reserve Bank of Malawi (RBM) to work towards establishing farmers' associations and funds to help smallholder farmers. 
These are the policies that have been implemented or are under process. However, the main question currently is whether Malawi can work towards increasing its share of macadamia exports in the global market? A value chain analysis conducted displays the current and future aspects of Macadamia production in Malawi. It has been found out that smallholder farmers do not possess the required technology to process the nuts, and therefore commercial estates take up the bulk of the value chains. Due to this, the margins are highly tilted towards the estates' sector, leaving the smallholder farmers at a disadvantage. With the global macadamia production expected to increase, efficient production could be an advantage for smallholder farmers.

There exists a high potential for Malawi to increase its share of macadamia exports in the global markets. To do so, a strategic development plan needs to be implemented [15]. First, financial constraints need to be addressed. One way to do so is to establish selfsustaining means of raising finance. This can include training farmers to govern savings and credit groups. Once this is done, the next motive should be to penetrate relevant markets, possibly by partnerships between public-private partnerships that introduce smallholder farmers into the value chain.

Moving on to its biggest consumers, it is essential to note that North America is labeled as the biggest market for macadamia nuts. A way forward would be to increase production to meet the demands of high potential consumer countries. This can be achieved by expanding production areas into the central and northern rain-fed areas in Malawi. All such steps need to be based on sufficient research and development on adapted cultivars of macadamia and the availability of quality planting material. Keeping the prospects in mind, macadamia production can be a way out of poverty for smallholder farmers. For this, the government must raise funds to help drive policies designed for improved production and growth.

\section{Challenges and Opportunities in Macadamia Production in Malawi}

\subsection{Access to Quality Seedlings}

Lack of access to quality seedlings is a significant challenge that many smallholders face in Malawi [32]. The country has a limited number of certified seedling supplies to carter to the growing demand for macadamia seedlings [27]. Another limiting factor is the general high-cost seedlings ( $£ 2.5$ seedling $\left.^{-1}\right)$, which becomes prohibitive for many smallholder farmers in the country). HIMACUL and some commercial estates are responding by increasing nursery/seedling production to be made available and affordable to smallholder farmers.

\subsection{Adaptability of Macadamia Cultivars}

The success of macadamia tree yields depends on its interaction with the growing area's environment (agro-ecological zone/AEZ). Malawi consists of eleven distinct AEZs, and a single district can have different microclimates within a single AEZ [33]. This causes varying responses in terms of crop growth and yields within the same district and may affect crop cultivars' harvesting patterns due to differences in altitude. For instance, differing climatic conditions in the macadamia growing regions of Australia were the primary reason for the poor performance of Hawaiian cultivars in the country, leading to lower yields and unpredictable nut quality [34]. In Australia, trees produce an average yield of $20 \mathrm{~kg}$ of nuts tree ${ }^{-1}$ as compared to $45 \mathrm{~kg}$ of nuts tree ${ }^{-1}$ in Hawaii. Generally, this is not unexpected as the Hawaiian cultivars were selected under totally different climatic conditions [34]. A similar phenomenon has been reported in Malawi, where nut yields of Hawaiian selections have been as low as $10 \mathrm{~kg}$ for nuts trees ${ }^{-1}$ [20]. The majority of macadamia cultivars grown in Malawi are Hawaiian selections introduced specifically for plantation production in the country's southern region after recommendations from research [35]. The promotion of smallholder macadamia production by Malawi's government has extended to the central (Ntchisi, Dowa, Kasungu, and Lilongwe) and northern (Rumphi, Chitipa, Mzimba, and Nkhatabay) regions of the country. 
Despite the promotion of smallholder macadamia production and the provision of extension services, macadamia yields among the small-holdings are still very low and are less than $\leq 200 \mathrm{~kg} \mathrm{ha}^{-1}$ than the ideal yield of $1200 \mathrm{~kg} \mathrm{ha}^{-1}$ [15]. Low productivity and poor quality reflect inadequate information on the right cultivars for production among the smallholder growing areas within the country. Figure 8 shows the performance of macadamia species grown by HIMACUL cooperatives in Malawi. Varying yields can be observed depending on the growing area, indicating that macadamia yield and suitability are subject to a cultivar-environment interaction. No research currently exists exploring the impact of climate on macadamia growth and development under smallholder production in Malawi [15]. Therefore, research is required to identify and recommend cultivars for the smallholder growing areas for optimum yields.

\subsection{Availability of Agricultural Extension Services}

The availability of agricultural extension staff and macadamia experts in the macadamia value chain in Malawi is minimal, and this has become less available after the completion of the Farm Income Diversification Programme and MSDP projects [25]. Smallholder macadamia agroforestry has not yet become self-sustainable, and many farmers have not yet reaped the long-term benefits of the crop. Consequently, trees have often been neglected, with farmers receiving little technical or managerial support. For macadamia nuts to remain viable in Malawi as a long-term initiative, providing smallholder farmers with the necessary extension services and technical support. Currently, cooperative extension services are a practical solution; for example, HIMACUL has successfully trained its lead/model farmers in good agroforestry practices, who are starting to train other farmers.

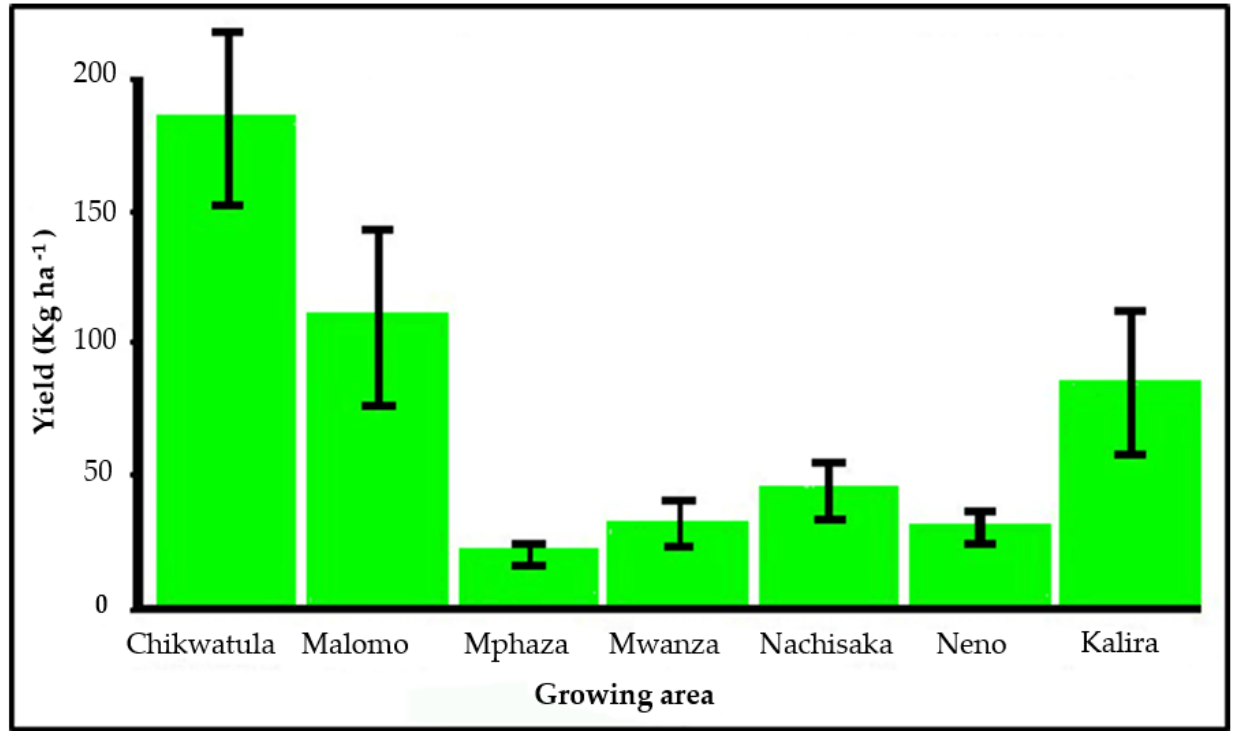

Figure 8. Macadamia yields in HIMACUL areas during the 2018/2019 growing season.

\subsection{Infrastructure Development}

Macadamia production and processing require sophisticated infrastructure and equipment (storage sheds, drying racks, a good network of roads, and a processing factory within the vicinity of production areas) to be put in place for profitability. Currently, macadamia processing companies are privately owned, with limited access for smallholder farmers, making it expensive for them due to distance. Smallholders cooperatives may transport their nuts over $600 \mathrm{~km}$ to be processed [15]. The solution could be through smallholder aggregation of nut in shell and investment in dehusking machinery at the cooperative level. 


\subsection{Pests and Diseases}

Pests and diseases are a significant challenge in macadamia production in Malawi. These can cause yield losses of up to $100 \%$ and affects the quality of the crop. Common pests of macadamia of significant importance in Malawi are fruit borers, tropical nut borers, stink bugs, and termites. Termites can be devastating to a field of macadamia trees, typically because they search for water, and can kill the trees by damaging root systems and bark around the tree's girth. The other pests typically render nut harvest damage and make them unfit for consumption.

\subsection{Insufficient Stakeholder Collaborations}

Dialogue and communication among the different stakeholders in Malawi's macadamia value chain are lacking [25]. Often there is rivalry among actors due to conflicting interests. To address this, sector associations should establish, adopt, and enforce codes of conduct to regulate sector players' practices. Furthermore, all actors should discuss a multi-stakeholder strategy to address the challenges facing the macadamia sub-sector.

\subsection{Government Policy Support}

The Malawi government, Ministry of Agriculture, Irrigation and Water Development in Malawi is responsible for agricultural policy and planning. The ministry is mandated to provide an enabling environment for the production of various crops in the country. According to our interviews with various Malawi stakeholders, we have observed that there is little or no support from the ministry on the macadamia value chain. Macadamia smallholders have reported the lack of agricultural advisory services, lack of organized markets for their crop, and the lack of support for infrastructure development from the ministry as it does to other crops such as maize and tobacco. However, the ministry could improve on these challenges through the following;

- The inclusion of macadamia courses in higher education institutions (as a stand-alone course or embedded in existing courses).

- The government should work with macadamia processors and marketers on setting fair and competitive prices for macadamia nuts, especially those sourced from smallholder farmers.

- The government should invest in macadamia processing infrastructure, similar to the already established auction holdings for the tobacco crop.

- The government should provide an enabling environment for other private investors to invest in the processing of macadamia nuts, which is currently monopolized by established commercial estates.

Despite the few government interventions in the macadamia value chain in Malawi, there has been some progress in terms of creating suitable policies for macadamia farmers. In 2017, Malawi's government enacted a policy that mandates that buyers of the crop to consider $60 \%$ of the smallholder crop as grade A. This was done to increase the profits for the smallholder farmers and to promote the crop. However, enforcing this policy is still a big challenge due to commercial estates and middlemen's monopoly. To address this challenge, the government needs to create a registry for all the smallholder producers and buyers of the crop for traceability purposes.

\subsection{Climate Change}

Macadamia production is a promising sub-sector in Malawi due to the country having a suitable climate and altitude. However, climate change represents significant threats to macadamia production. Extreme weather events such as heatwaves, flooding, and droughts have been highlighted as the key challenges to macadamia production, especially in the country's southern parts [6]. Barrueto et al. reported that changing climatic conditions cause shifts in land suitability, consequently affecting macadamia production [36]. To address the potential negative challenges of climate change on macadamia production in 
Malawi, there is a need to conduct land suitability predictions for the crop both currently and in the future. Such a study would assist in land use planning, and macadamia requires a high initial cost of establishment. In addition, addressing the problem of drought, we recommend using water conservation technologies such as mulching, rainwater harvesting, making basins around trees, manure application, and irrigation.

\section{Conclusions}

The macadamia sub-sector in Malawi has changed tremendously over the last decade and within the small plots of smallholders currently competing with other crops for land space. We observed little government-driven involvement in the sub-sector compared to the enormous investments the private sector is putting in place. We recommend active participation from Malawi's government in the macadamia value chain policy formulation, given its importance and contributions to Malawi's economy. Policies regarding market prices and exportation may assist smallholder farmers in getting better prices from their crops. The government also needs to provide agricultural advisory services and investments in infrastructure within the macadamia value chain for increased productivity.

We have identified that smallholder macadamia production in Malawi has received little attention, and cultivars may be grown in areas that may not be suitable, leading to lower yields. To further understand the productivity, it will be essential to evaluate climatic factors' influence on macadamia cultivar performance in the smallholder growing areas for recommendations of suitable cultivars for higher yields and returns. We also recommend tree management research, especially water conservation, irrigation, pest, and disease management, and soil nutritional studies.

We have also established that most of the macadamia nut exports from Malawi are generally in raw form. As such, they fetch a lower price market than processed products There is, therefore, a need to invest in the processing of macadamia products within Malawi to ensure that the country gets the profits it desires. However, this can only be achieved through policies that provide a suitable environment for investors.

Author Contributions: Conceptualization, E.J.Z., Y.N.A., and A.E.; methodology, K.M., and S.B.; writing-original draft preparation, E.J.Z., Y.N.A., and K.M.; writing-review and editing, E.J.Z., Y.N.A., K.M., S.B., A.E., and W.R.; All authors have read and agreed to the published version of the manuscript.

Funding: This research was funded by the Open University and the UK Research and Innovation through Global Challenges Research Fund project.

Institutional Review Board Statement: Not applicable.

Informed Consent Statement: Not applicable.

Data Availability Statement: The data presented in this study are available on request from the corresponding author.

Acknowledgments: The authors are grateful to the Open University and the UK Research and Innovation through Global Challenges Research Fund (GCRF) project for funding and academic guidance. Thanks also go to the Highland Macadamia Cooperative Union Limited smallholder farmers, specifically to Ken Mkangala for his useful comments. However, mistakes and omissions are our responsibility.

Conflicts of Interest: The authors declare no conflict of interest. 


\section{References}

1. Government of Malawi. Annual Economic Report; Government of Malawi: Malawi, Lilongwe, 2020; p. 223.

2. Chinyamunyamu, B. The Invisibilisation of Female Farmers from Agricultural Policies and Interventions: The case of the Malawi Farm Inputs Subsidy Programme (FISP). Leeds. 2014. Available online: http://etheses.whiterose.ac.uk/6564/1/Betty_ Chinyamunyamu_PhD_Thesis_11_April\%5B1\%5D.pdf (accessed on 8 January 2021).

3. Warnatzsch, E.A.; Reay, D.S.; Leggieri, M.C.; Battilani, P. Climate Change Impact on Aflatoxin Contamination Risk in Malawi's Maize Crops. Front. Sustain. Food Syst. 2020, 4, 1-13. [CrossRef]

4. Government of Malawi. Malawi National Resilience Strategy (NRS): Breaking the Cycle of Food Insecurity Duration. Government of Malawi: Lilongwe, Malawi, 2018.

5. Kerr, R.B.; Nyantakyi-Frimpong, H.; Dakishoni, L.; Lupafya, E.; Shumba, L.; Luginaah, I.; Snapp, S.S. Knowledge politics in participatory climate change adaptation research on agroecology in Malawi. Renew. Agric. Food Syst. 2018, 33, 238-251. [CrossRef]

6. Dougill, A.; Mkwambisi, D.; Vincent, K.; Archer, E.; Bhave, A.; Malinga, R.H.; Mataya, D.C. How Can We Improve the Use of Information for a Climate-Resilient Malawi? 2020. Available online: www.futureclimateafrica.org (accessed on 7 September 2019).

7. Adjimoti, G.O.; Kwadzo, G.T.; Sarpong, D.B. Input Policies and Crop Diversification: Evidence from the Collines Region in Benin. Input Policies Crop Diversif. Evid. Collines Reg. Benin 2017. [CrossRef]

8. Stevens, T.; Madani, K. Future climate impacts on maize farming and food security in Malawi. Sci. Rep. 2016, 6, 1-14. [CrossRef] [PubMed]

9. Warnatzsch, E.A.; Reay, D.S. Assessing climate change projections and impacts on Central Malawi's maize yield: The risk of maladaptation. Sci. Total Environ. 2020, 711, 134845. [CrossRef]

10. Government of Malawi. Malawi National Export Strategy; Government of Malawi: Lilongwe, Malawi, 2013; Volume 1, pp. 1-64.

11. FAO (Food and Agriculture Organization). Assessing the Policy Environment for Cash Crops in Malawi: What Could Hinder the Achievement of the National Export Strategy Objectives? Food and Agriculture Organization of the United Nations: FAO Agricultural Development Economics: Rome, Italy, 2017; p. 17.

12. Alam, M.; Hardner, C.; Nock, C.; O'Connor, K.; Topp, B. Historical and molecular evidence of genetic identity of macadamia cultivars HAES741 and HAES660. HortScience 2019, 54, 616-620. [CrossRef]

13. International Nut Council. Nuts and Dried Fruits—Statistical Yearbook 2019-2020; International Nut Council: Reus, Spain, 2019. [CrossRef]

14. White, N.; Hanan, J. A model of macadamia with application to pruning in orchard. Acta Hortic. 2016, 1109, 75-81. [CrossRef]

15. Toit, J.P.; Nankhuni, F.J.; Kanyamuka, J.S. Can. Malawi Increase its Share of the Global Macadamia Market? Opportunities and Threats to The Expansion of Malawi's Macadamia Industry; Michigan State University: East Lansing, MI, USA, 2017; p. 2017.

16. Rizvaan, K. Oil Seed Products Technical Working Group-Macadamia Sector Overview; AgDevCo.: Lilongwe, Malawi, 2016.

17. Irish Aid. Malawian Macadamias 2012-2020: Strategic Plan for the Malawian Macadamia Industry. Available online: http: //www.inclusivebusinesshub.org/wp-content/uploads/2016/05/MalawiMacadamiaStrategicPlan20122020.pdf (accessed on 28 October 2020).

18. Benson, T.; Mabiso, A.; Nankhuni, F. Detailed Crop Suitability Maps and an Agricultural Zonation Scheme for Malawi. Michigan, USA. 2016. Available online: http:/ / dec.usaid.gov / (accessed on 30 September 2020).

19. Hancock, W.M. Macadamia Reference Manual; The Government of Malawi: Blantyre, Malawi, 1991.

20. Green, P.I.M. Studies on the Control. of Growth and Development in Macadamia Integrifolia (Maiden and Betche); The University of Bath: Bath, UK, 1991.

21. Oakland Institute and the Alliance for Food Sovereignty in Africa (AFSA). Agroecology Case Studies; Drought Prone Malawi And Zambia Turn to Cassava Location. Oakland Institute: Oakland, CA, USA, 2016; pp. 1-4.

22. African Development Bank. Appraisal Report: Macadamia Smallholder Development Project. The African Development Bank: Abidjan, Nigeria, 1998. [CrossRef]

23. African Development Bank. Republic of Malawi Macadamia Smallholder Development Project: Project Completion Report; The African Development Bank: Abidjan, Nigeria, 2009.

24. Parshotam, A. Cultivating Smallholder Inclusion in Southern Africa's Macadamia Nut Value Chains; South African Institute of International Affairs: Pretoria, South Africa, 2018.

25. Evans, N. Macadamia Industry Consultation: Summary of findings; Evans Consulting: Lilongwe, Malawi, 2020.

26. Mkangala, K. Personal Interview. 2020.

27. Parshotam, A. Occasional Paper 278 Cultivating Smallholder Inclusion in Southern Africa'S Macadamia; South African Institute of International Affairs: Pretoria, South Africa, 2018.

28. Brandreth, W.J. Carbon Stock Assessment for the Climate-Smart Macadamia Agroforestry Plan. Vivo Project in Malawi; Imperial College London: London, UK, 2015.

29. Quiroz, A.; Kuepper, D.; Wachira, B.; Emmott, J. Value Chain Analysis of Value Chain Analysis of Macadamia Nuts in Kenya; The Centre for the Promotion of Imports from developing countries (CBI): Amsterdam, The Netherlands, 2019.

30. Gourichon, V.; Cameron, H.; Pernechele, A. Assessing the Policy Environment for Cash Crops in Malawi. 2017. Available online: https://ageconsearch.umn.edu/record/288998/ (accessed on 12 October 2020).

31. Nkhoma, P.R. The evolution of agricultural input subsidy programs: Contextualizing policy debates in Malawi's FISP. World Dev. Pers. 2018, 9, 12-17. [CrossRef] 
32. Government of Malawi. National Agricultural Investment Plan (NAIP); Government of Malawi: Lilongwe, Malawi, 2018.

33. Muteji, J.; Kabambe, V.; Shamie, L.W.Z.; Harawa, R. The Status of Fertilizer Recommendation in Malawi: Gaps Challenges and Opportunities. Malawi Soil Heal. Consort. 2015, 56, 1-40.

34. Radspinner, L.A. A Study of Variability in Macadamia Integrifolia Variety 'Keauhou' at Several Locations in Hawai' $i$; The University of Hawai'i: Honolulu, HI, USA, 1970.

35. Evans, N. Suitability Mapping of the Malawi Macadamia Industry; Irish Aid: Dublin, Ireland, 2008.

36. Barrueto, A.K.; Merz, J.; Hodel, E.; Eckert, S. The suitability of Macadamia and Juglans for cultivation in Nepal: An assessment based on spatial probability modelling using climate scenarios and in situ data. Reg. Environ. Chang. 2018, 18, 859-871. [CrossRef] 